\title{
Synchronous/Asynchronous Development Learning Environment (SADLE): Comparative with CMSs
}

\author{
Raafat George Saadé \\ Department of Decision Sciences and MIS, John Molson School \\ of Business, Concordia University, Montreal, Quebec, Canada
}

rsinfo@sympatico.ca

\begin{abstract}
The past ten years has seen a rapid increase in Internet use. Institutions and corporations are being continuously subjected to pressures related to maintaining the information on their web sites. Today, the way the web is managed and maintained is characterized by highly manual approaches. The objective of a successful and sustainable web will have to be significantly automated. "Content Management Systems (CMS)" have claimed to be one vehicle serving this objective.

CMS is a concept that embraces a set of processes that are highly contextual and therefore by default differ from case to case. Institutional needs are highly individualized and most agree that the solution to a specific CMS is a mixture of "buy\&build". Literature from CMS vendors should be taken with a grain of salt due to the fact that they are over-hyped and filled with jargon. The significance to senior managers is that they need to be aware of the CMS issues and associated costs, and consider efficiency and effectiveness which gives the biggest return on investment.

This article focuses on a specific application of CMSs, namely in the e-learning paradigm where these CMSs are arguably referred to learning management systems (LMSs). The article first presents a study that sought to explore the domain of 'content management systems (CMS)', compare some major CMSs that are being offered in the marketplace and discuss the differences in a design of a proposed "true" LMS referred to in this study as SADLE. In addition to design considerations that have not been considered by today's CMSs, practical suggestions towards a new e-learning paradigm are elaborated.
\end{abstract}

Keywords: Content Management Systems, Learning Management Systems, Online Courses, Online Pedagogy, Design, Synchronous, Asynchronous

Material published as part of this publication, either on-line or in print, is copyrighted by the Informing Science Institute. Permission to make digital or paper copy of part or all of these works for personal or classroom use is granted without fee provided that the copies are not made or distributed for profit or commercial advantage AND that copies 1) bear this notice in full and 2) give the full citation on the first page. It is permissible to abstract these works so long as credit is given. To copy in all other cases or to republish or to post on a server or to redistribute to lists requires specific permission and payment of a fee. Contact 0HPublisher@InformingScience.org to request redistribution permission.

\section{Introduction}

The past ten years has seen a rapid increase in Internet use. Institutions are being continuously subjected to pressures related to maintaining their web sites. The lack of proper management of out of date material, poor design and associated control of their web sites, lack of authority control and webmaster- 
created bottlenecks, ineffective assessment of efficiencies and effectiveness and weak development processes are just of few problems driving these pressures.

Today, the way the web is managed and maintained is evident. Unfortunately, it is characterized by highly manual approaches. The objective of a successful and sustainable web will have to be its significant automation. "Content Management Systems (CMS)" can be one vehicle serving this objective. A CMS is more of a concept than a product. It is a concept that embraces a set of processes. Processes that are associated to a concept are highly contextual and therefore by default differ from problem to problem. Institutional needs are highly individual and most agree that the solution to a specific CMS is a mixture of "buy\&build". The primary issue is to evaluate what we have to buy and how much should we build until we have what we need?

Literature from CMS vendors should be taken with a grain of salt due to the fact that they are over-hyped and filled with jargon. In fact the boundaries of the CMS concept are blurred and there is substantial overlap with other concepts such as document management systems, knowledge management systems, ecommerce systems, groupware, virtual learning environments and portals. There is yet to be a clear definition of what constitutes a CMS, and hence any system can in effect be called a CMS.

The nature of the CMS is that it devolves control over content to the owner rather than the technician and scales without increasing management overheads. This has been reported to lead to a six-figure sum. The significance of all that to senior managers is that they need to be aware of the CMS issues and associated costs, and considers efficiency and effectiveness which gives the biggest return on investment.

From an educational perspective, educational institutions have expanded from the traditional inclass environment to the new digital phenomenon where teaching is assisted by computers (Richardson \& Swan, 2003). Today, we find a vast amount of courses, seminars, certificates and other educational offerings on the Internet. This wave of educational material and online learning has challenged the effectiveness of the traditional educational approach still in place at universities and other education institutions. Consequently, these institutions are struggling to redefine and restructure their strategies in providing education and delivering knowledge (Association of European Universities, 1996). Many institutions have adopted content management systems with limited success. Resistance to its usage is still high.

The general consensus among analysts tracking the e-learning market is that company success is tied to real business objectives (clomedia, 2003). A learning management system (LMS) implementation should be approached with the discipline, hard goals, timeline and performance benchmarks of any asset management project. One should not get confused by a laundry list of features. Focus should be on what you want to accomplish from a business and an educational point of view and then identify need.

With today's student demographics, educational institutions are rushing to meet the needs of the new learner by designing and setting up online learning tools as support to the computer assisted classroom.

In online learning, there seems to be two major research clusters where one deals with the development of good designs while the other deals with the assessment of student's satisfaction with an online course as it relates to a traditional face-to-face course. There is a sense of great expectations surrounding the development and use of online courses because of its versatility, flexibility and personalization potential. Many researchers today (Saadé, 2003, Sunal et al., 2003, Poole et al., 2003, Shih, Munoz, \& Sanchez, 2006, Saadé and Bahli, 2005, Saadé and Kira, 2006, Saadé and Kira, 2007, Saadé, 2007, Saadé and Kira, 2009) are advocating that these expectation should be contrasted with proper empirical studies and rigorous results analysis evaluating the efficiency 
of the online learning courses that are being implemented. The implication to such type of research touches many domains due to the multi-dimensionality of online learning.

It is evident from the foregoing the effort required by the learner and the instructor in taking and in designing and implementing an online course. An online course includes different tools. Online learning tools can be defined as any web sites, software, or computer-assisted activities that intentionally focus on and facilitate learning on the Internet (Poole, Jackson, 2003). Learning tools that have been investigated by researchers include web based dynamic practice system, multimedia application and game based learning modules (Saadé, 2003, Sunal et al., 2003, Poole et al., 2003, Eklund and Eklund, 1996, Irani, 1998). These learning tools focus on specific learning aspects and try to meet the learning needs of a particular group of learners.

This document presents a study that sought to explore the domain of 'content management systems (CMS)'. Recall that a CMS is not really a product or a technology per se, but rather a term referring to a concept and that entails a wide range of processes and tools that will underpin the future large-scale enterprise web site.

\section{Issues in Learning Management Systems}

When you begin to evaluate learning management systems, you are going to hear a lot of terms that end in "-ity": high availability, usability, scalability, interoperability, stability and security. Let's quickly examine each of these issues and why they are critical to the function of any enterprise management system.

- High availability: The LMS must be robust enough to serve the diverse needs of thousands of learners, administrators, content builders and instructors simultaneously.

- Scalability: The infrastructure should be able to expand - or "scale"- to meet future growth, both in terms of the volume of instruction and the size of the student body.

- Usability: To support a host of automated and personalized services, such as self-paced and role-specific learning, the access, delivery and presentation of material must be easyto-use and highly intuitive-like surfing on the Web or shopping on Amazon.com.

- Interoperability: To support content from different sources and multiple vendors' hardware/software solutions, the LMS should be based on open industry standards for Web deployments (XML, SOAP or AQ) and support the major learning standards (AICC, SCORM, IMS and IEEE).

- Stability: The LMS infrastructure can reliably and effectively manage a large enterprise implementation running $24 \times 7$.

- Security: As with any outward-facing collaborative solution, the LMS can selectively limit and control access to online content, resources and back-end functions, both internally and externally, for its diverse user community.

Optimally, an LMS will consolidate mixed-media training initiatives, automate the selection and administration of courses, assemble and deliver learning content, measure learning effectiveness and integrate with other enterprise applications.

"One of our goals was to create a complete curriculum of online courses and develop a certification program for employees and partners of all skill levels," said Debra Morton, director of business systems for McDATA Corp., an open storage networking solution company based in Broomfield, Colo. "The LMS enables us to offer self-paced, self-service courses while providing us with the necessary assessment and reporting capabilities to help monitor and track the learning process throughout McDATA's entire workforce as well as our partner community," she added. 
General Physics, a workforce development company focused on technical and soft skills training, worked with Oracle iLearning to provide a Web-based training portal for power plant personnel of all energy companies. The LMS provides the platform and the portal, while General Physics provides the technical content. The portal enables administrators to assign, evaluate and track both knowledge-based and hands-on qualification tasks while giving supervisors the ability to manage and track their employees' success.

"The advantage of using a scalable solution was the ability to deliver more than 1,400 technical training lessons to energy companies of every size," said Russ Garrity, director of General Physics Energy Services. "Because of the LMS architecture, we can offer cost-effective Web-based courses that can be accessed quickly and easily by a dispersed workforce."

There are features and capabilities that become increasingly important as e-leaning usage grows. From an operational point of view, the LMS and its key components - content management, user administration and system administration - should be 100 percent Web-deployable, requiring no additional client applications. As with any enterprise application, the more the software is customized, the harder it is to maintain, upgrade and expand. In the past, a lot of companies overengineered their e-learning solutions, spending a lot of money on consulting and customizing their applications. Because the pedagogical and business models for online learning were still in their infancy (and evolving rapidly) and the educational goals and targets changed, the organizations were stuck with "hard-wired" solutions with limited flexibility and scale.

\section{The e-learning Phenomenon}

Although e-learning got off to a shaky start in the late 1990s, industry analysts are now bullish about the enabling technologies, notably enterprise learning management systems (LMSs), both in terms of growing adoption rates and quick return on investment (ROI). Whereas early LMS adopters focused on discrete e-learning projects that were limited in scope and required a lot of expensive customization, the trend today is toward consolidation and providing a single, common infrastructure to manage learning and training initiatives across the organization.

A learning management system provides the platform for the enterprise's online learning environment by enabling the management, delivery and tracking of blended learning (i.e., online and traditional classroom) for employees, stakeholders and customers. A robust LMS should integrate with other departments, such as human resources, accounting and e-commerce, so administrative and supervisory tasks can be streamlined and automated and the overall cost and impact of education can be tracked and quantified.

Furthermore, an LMS should support a collaborative learning community, offering multiple modes of learning - from self-paced coursework (Web-based seminars and classes, downloadable, CD-ROM and video content) to scheduled classes (live instruction in classroom settings or online) to group learning (online forums and chats). In its ability to integrate, organize and standardize learning across broad organizational requirements, the LMS model has been compared favorably to enterprise resource planning (ERP) solutions, which convert a company's backoffice into a seamlessly functioning whole.

Recognizing how integral education is to the operation and success of any organization, it is not surprising that e-learning is now on a parallel track with other large-scale enterprise implementations, such as ERP, customer relationship management (CRM) and supply chain management (SCM). As organizations transform into e-businesses, they move from a fragmented information culture populated with disparate legacy systems to what is known as a "contextual collaborative" culture - a real-time, knowledge-sharing system to coordinate business activities across the enterprise and extended supply chain (via enterprise portals, applications or EDI, electronic data interchange). 
This worldwide trend is reshaping the e-learning market as well. Instead of implementing and supporting a hodgepodge of stand-alone projects, companies are looking to extend the value of their e-learning resources to support their diverse education needs across business functions.

\section{Synchronous/Asynchronous Development Learning Environment - SADLE}

In a systems approach LMS development, the specifications are formed as a product of the mind of the designer. From this process a designer's image of the system emerges. The LMS presented in this study was designed by the instructor with the aim:

1. to get students more involved in the strategies by which they can test their knowledge of topics to be learned - self-directed learning

2. to provide them with the opportunity and environment to work together-collaboration, and

3. to ensure that support is available in two modes: on-demand and schedules - customer service

The second aim although may seem simply about working on projects in groups, it is actually more in line with the constructivism philosophy by the way the practicing is being promoted. In specific, students provided with two learning tools: a collaborative wiki-based tool to work on their project virtually and a multiple choice questions practice learning tool to use strategically (as they see fit for themselves) for testing their learning progress. They are encouraged to work together to answer the questions thereby giving them the opportunity to communicate about what they have learned and they are also instructed to identify the wrong questions with the incentive to gain further points. Constructivism is based on the premise that knowledge is constructed by the individual through his or her interactions with the environment. In the present case, the environment includes material resources, other students and interactive tools. Constructivism has its roots in cognitive psychology which holds that individuals build their own understanding of their world through experiences, maturation and interaction including other individuals.

The implications of constructivism for a learning environment include customization of curricula to prior knowledge, tailoring of teaching strategies to student backgrounds and employing openended questions that promote dialogue among learners. Also, the constructivist approach is viewed by many (including the authors of this paper) to be more than just activities. The mere fact that you provide the opportunity for the leaner to be part of their own learning process foster active involvement and learning which clearly demonstrates the more respect to the student as a learner and as a human being.

The design and implementation of SADLE used in this study meets at least partially the constructivism approach where learners are actually more active in the learning process by interacting with the learning tool, and they are given the opportunity to take part of their learning process by getting involved with others to score higher grades and find the mistakes.

The primary objective of the SADLE is the efficient development and effective delivery of domain specific knowledge. This learning goal is the driving force behind the knowledge construction, communication and delivery mechanism tenets including strategies that determine the relationships between learner and content, instructor and learner and among learners.

The key to implementing these strategies lies in the analogy between mental structures and processes and the associative structure and hyper-linking processes of the web. The challenge is not only to construct an instructional environment so that it accurately reflects the expert's (in this case the instructor) knowledge structure (Miller and Miller 1999), but also to build an environ- 
ment that facilities the associated processes. There is however a pit fall to the limitless hyperlinking possibilities of the web in that it can compromise the learning process and detour the learner from the prescribed learning activities. Organization, degree of navigation, design and implementation of appropriate e-pedagogies and level of interactivity are the primary critical decisions that the instructor needs to make during the development of the online course, if a faithful communication of the expert's knowledge is to be achieved (Miller and Miller 1999).

Retalis and Avgeriou (2002) explain that the underlying idea of modeling web-based instructional systems is an explicit division of the instructional system into specific subsystems. These subsystems should meet instructional and pedagogical principles elucidating communication between learner and content, instructor and learner and among learners. Retalis and Avgeriou (2002) proposed a web-based instructional system and described non-technical and technical components. Oliver et al. (1996), identify the constitutive elements of effective online learning environments. The present system (SADLE) builds on the subsystems identified by Retalis and Avgeriou (2002) and the constitutive elements presented by Oliver et al. (1996) by integrating pedagogical (learning) principles in the design. More specifically, the cognitive constructivism paradigm is elucidated into the subsystems.

An architectural blue print is presented in figures 1 and 2 .

- learner and instructor

- Learner and learner

- Learner and tutor
- Cognitive processes

- Virtual systems development

- scaffolding

- Case discussion
- EISEL

- Formative Assessment

Discussion

- Case Studies 
The customer (in this case the student) service component includes the primary stakeholders entailing most of the communications in the SADLE use, namely the learner and the instructor and responds to their individual and respective needs. The roles of each stakeholder involved in the instructional process are described (Lindner 2001). The self-directed learning component includes online interactive tools/objects as well as processes/procedures/rules that provide flexibility to the student learning process. The collaboration component entails the embedding and use of various pedagogical and instructional strategies supporting the interactive learning tools.

\section{Customer Service}

The stakeholders and their roles are shown in table 1. The OES does not entail any physical classes. However, there are tutorials given by a tutor to help students enhance their productivity skills. This includes learning how to use different desktop software such as MS Access and learning basic html.

Table 1: Stakeholders and Associated Roles.

\begin{tabular}{|c|c|}
\hline $\begin{array}{l}\text { Stakeholders } \\
\text { (Use Question Cen- } \\
\text { ter) }\end{array}$ & Role \\
\hline Student & $\begin{array}{l}\text { - Browse question that have already been asked and answered } \\
\text { - If question answer set is available then } \\
\circ \text { Read } \\
\circ \text { Rate } \\
\text { - If question answer set is not available or what is available is not } \\
\text { sufficient then complete the question form. } \\
\circ \text { Ask question } \\
\circ \text { Categorize question type for specificity and effectiveness } \\
\circ \text { Specify if question is private or can be public to the bene- } \\
\text { fit of the other students } \\
\circ \text { Attach file if required }\end{array}$ \\
\hline Professor & $\begin{array}{l}\text { - } \text { Monitor progress of questions and answers } \\
\text { - Respond to question within reasonable pre-specified times } \\
\text { - } \text { Rate questions for importance } \\
\text { - } \quad \text { Monitor quality of answers by TAs }\end{array}$ \\
\hline $\begin{array}{l}\text { Teaching Assistant, } \\
\text { TA }\end{array}$ & $\begin{array}{l}\text { - Respond to students' emails within reasonable time } \\
\text { - Provide resources when required } \\
\text { - Provide assistance } \\
\quad \text { O Technical } \\
\circ \text { Operational } \\
\circ \text { Content }\end{array}$ \\
\hline
\end{tabular}

\section{Self-directed Component}

The self-directed component includes the interactive learning tools addressing the following issues:

- Learning goals to be met

- What online activities would help meet these learning goals

- Rules and processes to provide the opportunity for self-directed learning such as

○ No weekly deadlines

- Flexibility in completing requirements for online activities 
○ Ill-defined submission/participation specifications

- Opportunity to define and scope their own work provided they deliver what they promise

- Identify minimum limits for participation but do not limit the maximum amount of participation. This approach requires that more participation is linked to scores of some sort such as a running cumulative average of participation.

\section{Collaboration Component}

The collaboration component entails the use of pedagogical and instructional strategies supporting learning. To that effect, the collaboration component is primarily concerned with learning theory that can be beneficially mapped to online environments. More specifically, is to answer the question on how the content can be used effectively via the learning/pedagogical strategies and peer to peer interaction to actually achieve the specified learning goals. This includes the following:

- Constructivism

- Problem based learning or case based learning

- Scaffolding

- Peer assessment

- Discussion groups

- Case writing

- Project development

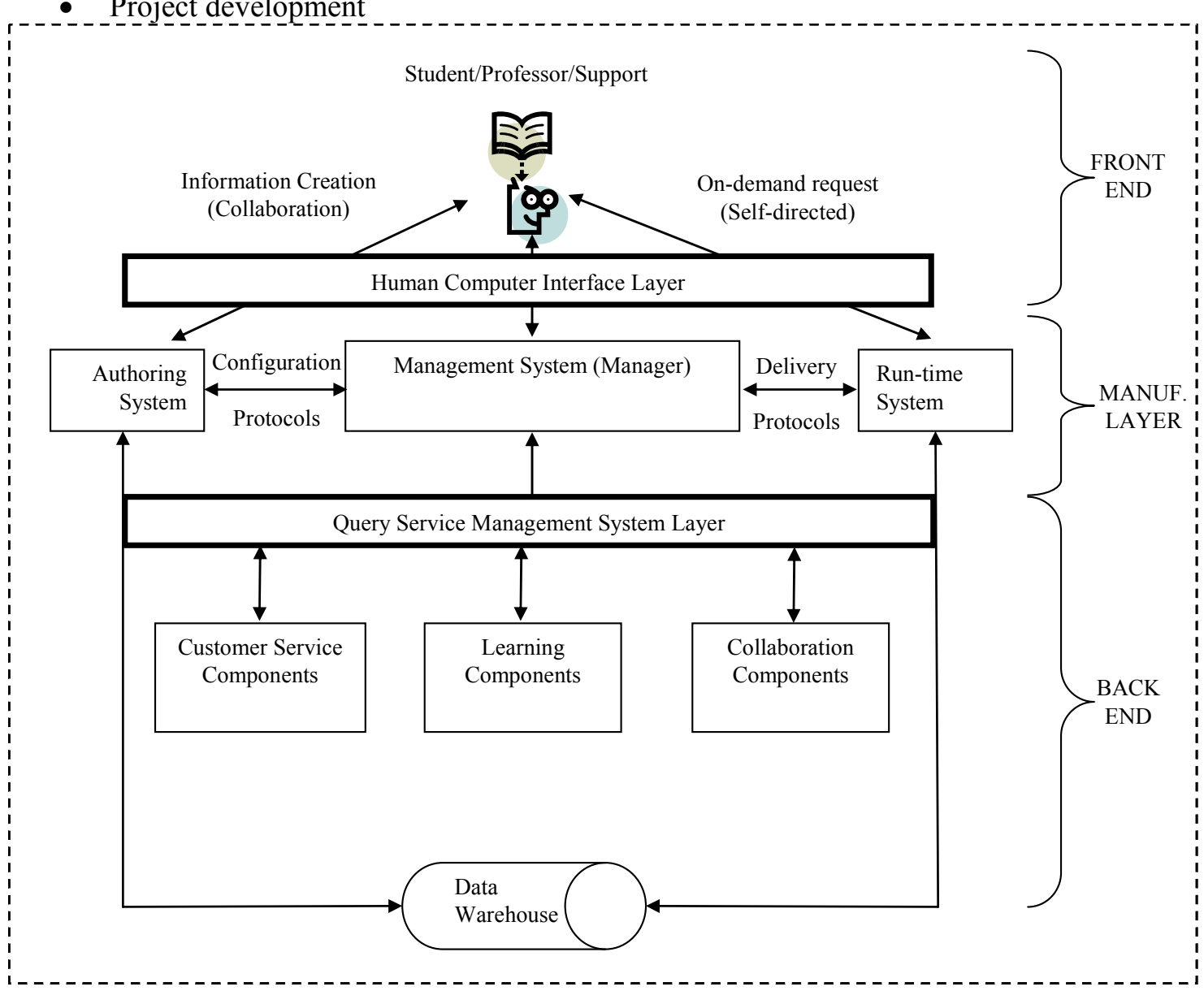

Figure 2: Conceptual framework for SADLE 
Figure 2 presents a conceptual level framework of SADLE. This framework entails three layers where the top layer is the human-computer interaction layer (front-end); the middle layer is the content management layer - creation to delivery (manufacturing layer); and the third layer includes the data management layer (backend).

SADLE is web-based and includes both the content/knowledge and process components. It is not designed to store and retrieve content, but is an agile environment with management functionalities to produce and deliver knowledge content effectively and efficiently. The SADLE does not compromise the advantages of the face to face environment and in fact enhances them with elements such as: interactivity, time and space flexibility, virtual collaborative learning environment, peer support, and on-demand support. All these elements can also be delivered in asynchronous as well as synchronous modes. SADLE is designed in line with the concept of product families classified into one of three types: (1) role objects, (2) service objects, and (3) learning object. For each type it has a unified front-end easily plugged into the SADLE by a relevant organizer. All product family types share the same back-end structure which is database-driven.

\section{Comparative Analysis}

Table 2 presents a comparison (by major feature category) of SADLE with 5 major learning management systems while table 3 shows the details to the features. It is worth noting in table 2 that integrated pedagogical strategies have not been part of the design of the other LMSs. Regarding SADLE being a free product, the author has inserted a question mark to indicate that this decision has not been done as it has been developed and used internally. In terms of scalability, SADLE is now being used for 3 courses serving around 4000 students annually. It is also now being used as a computer supported tool for 6 large face-to-face classes (120-300 students).

Table 2: Comparison by major feature category.

\begin{tabular}{|l|c|c|c|c|c|c|}
\hline \multicolumn{1}{|c|}{ Groups } & Angel & Blackboard & Moodle & WebCT & Whiteboard & SADLE \\
\hline $\begin{array}{l}\text { Extensive instructional } \\
\text { designer supports }\end{array}$ & $\checkmark$ & $\checkmark$ & $\checkmark$ & $\checkmark$ & & $\checkmark$ \\
\hline $\begin{array}{l}\text { Extensive instructor } \\
\text { supports }\end{array}$ & $\checkmark$ & $\checkmark$ & $\checkmark$ & $\checkmark$ & & $\checkmark$ \\
\hline $\begin{array}{l}\text { Extensive registrar } \\
\text { supports }\end{array}$ & $\checkmark$ & & & $\checkmark$ & & $\checkmark$ \\
\hline Free products & $\checkmark$ & $\checkmark$ & $\checkmark$ & $\checkmark$ & & $?$ \\
\hline Hosted products & $\checkmark$ & $\checkmark$ & $\checkmark$ & $\checkmark$ & \\
\hline $\begin{array}{l}\text { Instructional standards } \\
\text { conforming products }\end{array}$ & $\checkmark$ & $\checkmark$ & & $\checkmark$ & $\checkmark$ \\
\hline Open source products & & & & & & $\checkmark$ \\
\hline $\begin{array}{l}\text { Products with integrated } \\
\text { learning strategies }\end{array}$ & & & & $\checkmark$ & & $\checkmark$ \\
\hline $\begin{array}{l}\text { Products with published } \\
\text { studies }\end{array}$ & & & & & & \\
\hline
\end{tabular}




\section{Explanation of groups:}

- Extensive Instructional Designer Supports: Extensive Instructional Designer Supports include products that have features for instructional designers, such as Instructional Design Tools, Customized look and feel, and Course Layout Templates.

- Extensive Instructor Supports: Extensive Instructor Supports include products that have features for instructors, including Course Management, Instructor Helpdesk, Online Grading Tools, Student Tracking, and Automated Testing and Scoring.

- Extensive Registrar Supports: Extensive Registrar Supports include products that have features for registrars, such as Registration and Secure Transactions.

- Free Products: Free products have no start-up cost and no ongoing costs paid to the software supplier or host service.

- Hosted Products: With Hosted Products the online learning application provider furnishes the application with the server and technical support from their location so the institution does not provide any hardware.

- Instructional Standards Conforming Products: Instructional standards compliance concerns how well a product conforms to standards for sharing instructional materials with other online learning systems.

- Open Source Products: Open Source means that the online learning software system is developed, maintained and distributed in a free manner that preserves future users' ability to view and modify the source code.

- Products with integrated learning strategies: Integration

- Products with published studies: Integration

Table 3. Comparison by feature.

\begin{tabular}{|l|l|c|c|c|c|c|c|}
\hline & Feature & Angel & Blackboard & Moodle & WebCT & Whiteboard & SADLE \\
\hline 1 & $\begin{array}{l}\text { Accessibility Compli- } \\
\text { ance }\end{array}$ & 5 & 4 & 2 & 4 & 1 & 3 \\
\hline 2 & Authentication & 4 & 3 & 2 & 5 & 2 & 4 \\
\hline 3 & $\begin{array}{l}\text { Automated Testing and } \\
\text { Scoring }\end{array}$ & 5 & 4 & 4 & 4 & 2 & 5 \\
\hline 4 & $\begin{array}{l}\text { Calendar/Progress Re- } \\
\text { view }\end{array}$ & 5 & 4 & 2 & 3 & 2 & 5 \\
\hline 5 & Content Sharing/Reuse & 3 & 4 & 1 & 3 & 1 & 5 \\
\hline 6 & Costs & Per user & Per user & Free & Per user & Free & N/A \\
\hline 7 & Course Authorization & 5 & 4 & 3 & 4 & 3 & 5 \\
\hline 8 & Course Management & 4 & 2 & 2 & 4 & 1 & 4 \\
\hline 9 & Course Templates & 4 & 3 & 3 & 4 & 1 & 4 \\
\hline 10 & $\begin{array}{l}\text { Curriculum Manage- } \\
\text { ment }\end{array}$ & 3 & 1 & 1 & 2 & 1 & 4 \\
\hline $\mathbf{1 1}$ & $\begin{array}{l}\text { Customized Look and } \\
\text { Feel }\end{array}$ & $\mathbf{4}$ & $\mathbf{3}$ & $\mathbf{3}$ & $\mathbf{3}$ & $\mathbf{2}$ & $\mathbf{2}$ \\
\hline 12 & Database & SQL & NR & MySQL & NR & MySQL & MySQL, \\
\hline 13 & Discussion Forums & 5 & 3 & 4 & 4 & 2 & 5 \\
\hline 14 & File Exchange & 5 & 3 & 2 & 3 & 2 & 5 \\
\hline 15 & Group work & 3 & 2 & 2 & 3 & 1 & 4 \\
\hline 16 & Hosted Services & 5 & 5 & 5 & 5 & 1 & 5 \\
\hline
\end{tabular}




\begin{tabular}{|c|l|c|c|c|c|c|c|}
\hline & Feature & Angel & Blackboard & Moodle & WebCT & Whiteboard & SADLE \\
\hline 17 & $\begin{array}{l}\text { Instructional Design } \\
\text { Tools }\end{array}$ & 3 & 2 & 3 & 2 & 1 & 5 \\
\hline $\mathbf{1 8}$ & $\begin{array}{l}\text { Instructional Stan- } \\
\text { dards Compliance }\end{array}$ & $\mathbf{4}$ & $\mathbf{4}$ & $\mathbf{2}$ & $\mathbf{4}$ & $\mathbf{2}$ & $\mathbf{2}$ \\
\hline 19 & Internal Email & 4 & 3 & 2 & 5 & 1 & 4 \\
\hline 20 & Online Grading Tools & 4 & 5 & 4 & 5 & 3 & 4 \\
\hline 21 & Online Journal/Notes & 5 & 2 & 3 & 3 & 1 & 3 \\
\hline $\mathbf{2 2}$ & Open Source & No & No & Yes & No & Yes & No \\
\hline 23 & Orientation/Help & 3 & 2 & 2 & 2 & 2 & 5 \\
\hline 24 & Live lectures & 1 & 1 & 1 & 1 & 1 & 5 \\
\hline 25 & $\begin{array}{l}\text { Live communica- } \\
\text { tions/support }\end{array}$ & 1 & 1 & 1 & 1 & 1 & 5 \\
\hline 26 & Real-time Chat & 5 & 4 & 2 & 4 & 1 & 5 \\
\hline 27 & Registration Integration & 5 & 5 & 2 & 3 & 2 & 3 \\
\hline 28 & $\begin{array}{l}\text { Searching Within } \\
\text { Course }\end{array}$ & 3 & 2 & 2 & 2 & 1 & 4 \\
\hline 29 & Self-assessment & 4 & 3 & 2 & 4 & 1 & 5 \\
\hline 30 & $\begin{array}{l}\text { Student Community } \\
\text { Building }\end{array}$ & 3 & 2 & 1 & 2 & 1 & 4 \\
\hline 31 & Student Tracking & 4 & 3 & 4 & 4 & 2 & 5 \\
\hline 32 & Video Services & 2 & 1 & 1 & 1 & 1 & 5 \\
\hline 33 & Whiteboard & 3 & 3 & 1 & 3 & 1 & 5 \\
\hline 34 & Instructional design & 2 & 2 & 1 & 2 & 1 & 5 \\
\hline 35 & $\begin{array}{l}\text { Integrated learning } \\
\text { strategies }\end{array}$ & 2 & 2 & 1 & 2 & 1 & 5 \\
\hline 36 & Testing capabilities & 3 & 2 & 2 & 3 & 2 & 5 \\
\hline 37 & $\begin{array}{l}\text { Pedagogical considera- } \\
\text { tions }\end{array}$ & 2 & 2 & 1 & 2 & 1 & 5 \\
\hline 38 & Publications & 2 & 2 & 1 & 2 & 1 & 5 \\
\hline 39 & $\begin{array}{l}\text { Assessment of effec- } \\
\text { tiveness }\end{array}$ & NS & NS & NS & NS & NS & YES \\
\hline 40 & Assessment of learning & 1 & 1 & 1 & 1 & 1 & YES \\
\hline 15 & None; 2-Few; 3-Moderate & 2 & & 1 & 1 \\
\hline
\end{tabular}

1=None; $2=$ Few; 3=Moderate amount; 4=Many; 5=Comprehensive; NR=Not reported; NS=Not studied; N/A=Not applicable.

\section{Discussion and Concluding Remarks}

The stakes in online courses delivery in higher education are high. The issues of concern (which are design variables at the same time) include quality, learning effectiveness, efficiency cycle and satisfaction. The author would go as far as calling those concerns the 4 pillars of sustained online learning. Quality implies monitoring and controls initiatives; learning effectiveness requires a serious discussion on situational pedagogies appropriate to the learner and learning process. Efficiency cycle constitutes the mechanisms that need to be put in place for the manufacturing and delivery of content. Satisfaction measures, quantifies and qualifies the consumer's interaction with online learning. SADLE is a proposed system in place today that has evolved over 8 years of continuous development and refinement. In this article we aim to demonstrate the significant elements of SADLE to learning as compared to the many other systems used today. Although these LMSs look impressive in technology considerations and content management requirements, they are exactly that - managers of content. They have completely forgotten, intentionally or unintentionally ignored, and completely bypassed all the elements necessary to take advantage of technologies for learning and their assessment of how much learning has actually occurred. Their 
failure in this author's opinion is a design one: the design is a direct mapping of face to face instructional strategies into the online environment.

Although it is beyond the scope of this article to describe the details to SADLE that is used today, the author feels that it is worth mentioning some design features and their effects with the aim to provide some insights on what is "under the hood" - so to speak. SADLE entails an agile information repository (IR) that is flexible through modularity, and standardization. The IR consists of both information content and structure (denoting the backend design) specifying enhanced access and maintenance to information.

SADLE views online courses as products in a supply chain process. It also considers institutions as an integrated component of the LMS and not a user of the LMS. With that in mind it is important to note that institutions in the information learning product market need to define their information product repository. This requires the institutions to think seriously and make proper assessments of their own environment(s) and across their particular products and markets. To that effect institutions of higher education need to re-establish the architecture of their product family or portfolio rather than to directly re-create same versions and a copy of others' courses as they existed in the original's mind (different time, different place, and different context). This author strongly suggests that institutions who wish to enter or enhance their online products/courses address the following:

- Portfolio of product families

- Basic chunks of underlying information and knowledge units

- Inclusion and exclusion criteria for

- Online courses to be considered as candidate information products,

- Design considerations

- Pedagogical considerations

- Stakeholders

- Learner

- Teachers

- Teaching assistants

- Managers

- Architecture of information and knowledge units

- Commonalities

- Specificities,

- What level of granularity for these information units which can reasonably facilitate a strategy of flexibility, re-cyclability and inter-operability and serve customized products,

- What different standard operating procedures (SOPs) need to be put in place to ensure accountability, control, and quality,

- What are the different pedagogical considerations that can be of use to information products / online courses environments?

Once the institution defines the structure of its repository and establishes an inventory of information units within that structure, it must then carefully setup the standard mechanisms by which its professors may integrate or combine information units within pre-specified pedagogical frameworks.

In conclusion, the primary goal of this article is a call to break out of the cycle of the today LMS established online learning paradigm. These LMSs hardly address and represent the complexities of learning. Our aim is to show what is lacking and more importantly that these lacking elements 
constitute the more important part of online learning. This author seeks an updated paradigm for e-learning.

\section{References}

Association of European Universities. (1996). Restructuring the university: Universities and the challenge of new technologies," CRE Document No. 1 .

Eklund, J., \& Eklund, P. (1996). Integrating the web and the teaching of technology: Cases across two universities. Proceedings of the AusWeb96, The Second Australian WorldWideWeb Conference, Gold Coast, Australia. Retrieved Feb, 2004 from http://wwwdev.scu.edu.au/sponsored/ausweb/ausweb96/educn/eklund2

Irani, T. (1998). Communication potential, information richness and attitude: A study of computer mediated communication in the ALN classroom. ALM Magazine, 2(1).

Lindner, R. (2001). Expertise and role identification for learning environments (ERILE). Proposed Standard Draft for German DIN NI-36 (planned to be a mirror for the ISO/IEC JTC1 SC36). Retrieved from http://www.igd.fhg.de/ lindner/PROMETEUS/SIG-DESIGN Meeting-Point.html

Miller, M. S., \& Miller, L. K. (1999). Using instructional theory to facilitate communication in web-based courses. Educational Technology \& Society, (2:3). Retrieved from http://ifets.ieee.org/periodical/vol 3 99/miller.html

Oliver, R., Herrington, J., \& Omari, A. (1996). Creating effective instructional materials for the world wide web. AUSWEB96, 1996, pp. 485-491.

Poole, B. J., \& Lorrie, J. (2003). Education online: Tools for online learning. Education for an information age, teaching in the computerized classroom (4th ed.).

Richardson, C. J., \& Swan, K. (2003). Examining social presence in online courses in relation to students' perceived learning and satisfaction. $J A L N, 7(1), 68-88$.

Retalis, S., \& Avgeriou, P. (2002). Modelling web-based instructional systems. Journal of Information Technology Education, 1(1), 25-42. Retrieved from http://www.jite.org/documents/Vol1/v1n1p025042.pdf

Saadé, G. R. (2003). Web-based educational information system for enhanced learning, (EISEL): Student assessment. Journal of Information Technology Education, 2, 267-277. Retrieved from http://jite.org/documents/Vol2/v2p267-277-26.pdf

Saadé, G. R. (2007). Dimensions of perceived usefulness: Toward enhanced assessment. Decision Sciences - Journal of Innovation Education, 5(2), 289-310.

Saadé, G. R., \& Bahli, B. (2005). The impact of cognitive absorption on perceived usefulness and perceived ease of use in on-line learning: An extension of the technology acceptance model. Information and Management, 42(2), 317-327.

Saadé, G. R., \& Kira, D. (2006). The emotional state of technology acceptance. Journal of Issues in Informing Science and Information Technology, 3, 529-539.

Saadé, G. R., Kira, D., \& He X. (2006). Exploring Dimensions to Online Learning. Computers in Human Behavior, 23(4), 1721-1739.

Saadé, G. R., \& Kira, D. (2009). Computer anxiety in e-learning: The effect of computer self-efficacy. Journal of Information Technology Education, 8, 177-191. Retrieved from http://www.jite.org/documents/Vol8/JITEv8p177-191Saade724.pdf

Shih, P., Munoz, D., \& Sanchez, F. (2006). The effect of previous experience with information and communication technologies on performance in a Web-based learning program. Computer and Human Behavior, 22(6), 962-970. 
Sunal, W. D., Sunal, S. C., Odell, R. M., \& Sundberg, A. C. (2003). Research-supported best practices for developing online learning. The Journal of Interactive Online Learning, 2(1), 1-40.

\section{Biography}

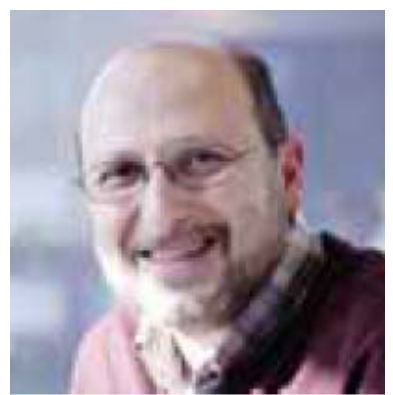

Raafat George Saadé is a lecturer at the Department of Decision Sciences and Management of Information Systems, John Molson School of Business, Concordia University, Montreal Canada. Dr. Saadé received his Ph.D. from Concordia University after which he won the National Science and Engineering Research Council (NSERC) postdoctoral research award (2 years) and which he completed at McGill University. Dr. Saadé has published papers in Information and Management, Expert Systems with Applications, Journal of Asynchronous Learning Networks, Decision Sciences, and others. He is the associate editor of the Journal of Information and Information Technology in Organizations and a member of the Informing Sciences Institute. Dr. Saadé is engaged in three research pipelines: e-Learning, e-Health and Supply Chain of Digital Information Products. 